\title{
ORGANIZAR: SUSPENSIÓN DE LA MORALIDAD Y RECIPROCIDAD NEGATIVA ${ }^{1}$
}

\author{
Paz MORENO FELIÚ \\ $U N E D$
}

ABSTRACT: Taking the concept of reciprocity as its starting point of discussion, the author proposes the analysis of negative reciprocity as a necessary and substantive aspect of the general concept of reciprocity. Reciprocity is based on a shared morality in its positive forms and on the break, reverse or suspension of the moral order in its negative forms. The discussion is based on the ethnographic account of the social relations present among inmates in the Auschwitz concentration camp. The Auschwitz extreme case provides on the one hand, a whole range of nuances and complex articulations regarding different orders of morality, transfer of resources and power hierarchies. On the other, it shows the usefulness of a concept of reciprocity that incorporates the negative side of reciprocal relations.

El objeto de este artículo es analizar la reciprocidad a través de lo que podríamos denominar la "cara oscura» de esta fuerza social: la reciprocidad negativa. La importancia de "tomar" o "quitar" parece estar implícita en el propio concepto, tanto desde el punto de vista de su construcción teórica, como desde el de las descripciones históricas y etnográficas. Pero la reciprocidad negativa no debe plantearse en términos de la ausencia o la transgresión de unas relaciones recíprocas consideradas armónicas y benéficas para la "sociedad». Al hacer hincapié en los componentes predatorios que se dan en estas relaciones, queremos subrayar su inextricable conexión con los mismos aspectos que habi-

1 Este artículo continúa el análisis desarrollado por MORENO y NAROTZKY (2000). Se encuadra en el trabajo que estamos realizando en el proyecto de investigación "La reciprocidad como recurso humano" PB98-1238, financiado por el Programa Sectorial de Promoción General del Conocimiento, Ministerio de Ciencia y Tecnología. 
tualmente se consideran positivos. El valor teórico del concepto radica en su capacidad para explicar cómo se produce esta articulación.

El artículo se basa en el análisis etnográfico de la reciprocidad negativa (lo que los internos denominaban "organizar») en los campos de concentración de Auschwitz.

Auschwitz comprendía una compleja red de subcampos (llegaron a ser más de cuarenta), administrados y dependientes de tres grandes centros (Czech, 1978, 1990; Dwork y Van Pelt, 1996): Auschwitz I, o campo principal; Auschwitz II o Birkenau, situado a $3 \mathrm{Km}$. del campo principal que era al mismo tiempo campo de concentración (desde octubre de 1942 albergaba el campo de mujeres así como los campos de familia de gitanos y judíos checos), campo de trabajo y campo de exterminio (desde la primavera de 1942 hasta noviembre de 1944); por último, Auschwitz III, también llamado Monowitz o Buna que era un campo de trabajo centrado en la fábrica que la compañía IG Farben construyó allí para producir caucho sintético. La cifra media de prisioneros oscilaba, según las épocas, entre 80.000 y 120.000 (Czech 1990). En total entre mayo de 1940 y enero de 1945 se registraron en Auschwitz unos 405.000 reclusos de los que más de la mitad perecieron. Estas cifras se refieren a todo el complejo, pero no incluyen el cerca de millón de personas exterminadas en las cámaras de gas de Birkenau. La mayoría de los prisioneros ignoraban la magnitud de Auschwitz. Desde un punto de vista externo podemos representarlo como un triángulo cuyos vértices serían las cámaras de gas del campo de exterminio de Birkenau, la fábrica de caucho sintético (Buna) en Monowitz y las políticas concentracionarias de Auschwitz I.

El caso extremo de Auschwitz nos brinda, por una parte, una amplia gama de matices y complejas articulaciones de diversos órdenes de moralidad en conflicto, de transferencias de recursos y de jerarquías de poder. Por otra, muestra la utilidad de un concepto de reciprocidad que incorpore la faceta negativa de las relaciones recíprocas.

La principal fuente de nuestra reconstrucción etnográfica son las memorias escritas por los antiguos prisioneros. En nuestra lectura de las memorias, el análisis de los textos como texto ha precedido a su uso como documento etnográfico. A partir de ahí, hemos comparado las memorias y observado sus relaciones con los sucesos que relataban, y con la gran variedad de formas en que estos sucesos se interpretaban por parte de distintos memorialistas, e incluso por parte del mismo autor en diferentes contextos. También hemos tenido en 
cuenta la peculiar cronología tanto de las memorias como de su recepción social, pero no nos hemos ocupado aquí del problema de los distintos usos, apropiaciones e interpretaciones interesadas que se han hecho y se hacen de los campos de concentración.

\section{Relaciones sociales en los campos de Auschwitz}

Desde un punto de vista etnográfico resulta más fácil describir las regulaciones internas de los campos que la variedad y complejidad de las situaciones sociales que surgieron en ellos. Así desde la primera perspectiva, Auschwitz seguía el doble sistema establecido por Eickel para el campo modelo y pionero de Dachau: por una parte, la estructura organizativa y administrativa de un número relativamente bajo de SS y guardianes subordinados del campo (desde el comandante, los médicos al último vigilante ucraniano) y por otra, los dispositivos y mecanismos que permitían ordenar y dominar a una masa confusa de prisioneros, cuya vida transcurría en un universo social difícilmente controlable por ellos mismos: la violencia institucionalizada, tanto la de las autoridades del campo contra las víctimas como la existente entre los propios prisioneros, se ejercía en las formas más extremas conocidas en ninguna sociedad; el hambre era constante; el clima extremo; el agua no potable; las jornadas y el tipo de trabajo, extenuantes; las epidemias de tifus y las enfermedades llevaban a muchos prisioneros al hospital, lugar del que era casi imposible salir con vida. Las altísimas probabilidades de morir se agravaban por la frecuencia de las selecciones periódicas que enviaban a los definidos como «no aptos para el trabajo" al crematorio.

Hoss, el primer comandante y artífice de Auschwitz, puso en marcha la estructura de control interno del campo mediante la creación de distintos rangos antagónicos entre los propios prisioneros, a la cabeza de los cuales se situaban los llamados "prisioneros funcionarios», "preeminentes» o "aristócratas" (jefe de campo, jefe de oficinistas del campo, jefe de estadísticas del campo, jefe de barracones, jefe de patrullas de trabajo, jefe de cada barracón, jefe de cada patrulla de trabajo (kapo), oficinistas de barracones, auxiliares, ayudantes, o todos aquellos que ocupaban posiciones especiales, como traductores, músicos, médicos, cocineros, etc.) Su importancia era tal que, incluso la historia de las penalidades del campo, obliga a diferenciar entre las primeras épocas, cuando la mayor parte de las posiciones de rango estaban 
ocupadas por presos comunes, de etapas posteriores a la marcha de Höss en las que algunos prisioneros políticos lograron ocupar puestos relevantes, sobre todo en los hospitales.

Ahora bien, la propia estructura del sistema, que idealmente distinguía con nitidez entre los dirigentes del campo y los prisioneros-funcionarios que actuaban como agentes necesarios para que se cumpliesen las órdenes, provocó, en la práctica, que estos últimos actuasen a su vez como "dirigentes» particulares, que sometían a los otros prisioneros a su propio poder. En este sentido, podemos observar cómo, por el propio diseño del sistema, en los campos se originaron una amplia gama de situaciones y actividades que iban desde aquellas que, como veremos, estaban expresamente prohibidas en todas las regulaciones del campo, hasta la aparición de nuevas normas y conductas que hicieron posible que algunos prisioneros creyesen que su conducta era decisiva para aumentar sus difíciles posibilidades de supervivencia.

Las extendidas redes de alianza que mantenían los prisioneros-funcionarios con algunos SS, con el resto de los internos llamados "aristócratas" y con los trabajadores civiles, así como las redes clientelares en las que participaban otros prisioneros subordinados les ayudaban a mantener su incierta situación de privilegio y poder, al tiempo que reforzaban el diseño del sistema que exigía que el prisionero corriente fuese una especie de mónada sin vínculos ${ }^{2}$ : la despersonalización inicial, violentamente sufrida por todos los prisioneros al llegar al campo, cuando les despojaban de su nombre propio, de todas sus pertenencias, y en el caso de los judíos de casi toda su familia y conocidos era un requisito necesario para el funcionamiento interno del campo. Su base (en la que hay que tener en cuenta que el número de guardianes y funcionarios oficiales era relativamente bajo) era contar con un batallón jerárquico de prisioneros que desconfiasen unos de otros y pugnasen entre sí. Así, el que fuera Comandante del complejo Auschwitz hasta 1943, Rudolf Höss, expresa claramente la necesidad de antagonismo y atomización entre los prisioneros, incluso cuando estos procedían de algún tipo de comunidad (nacional o religiosa) que supusiese que iban a organizarse colectivamente. «En los campos de concentración

2 No olvidemos que, a diferencia de otros sistemas penales, la mayoría de los prisioneros de un campo de concentración no han sido apresados por sus acciones, sino por lo que son: civiles que pertenecen a un grupo "enemigo", cuyos miembros son inasimilables para el modelo de sociedad que se pretende construir. En este mismo sentido se expresa BAUMAN (1989) cuando analiza el exterminio recurriendo a los modelos de la cirugía y la jardinería. 
las rivalidades eran alentadas y mantenidas por las autoridades para impedir cualquier unión fuerte entre los prisioneros. No sólo las diferencias políticas, sino también el antagonismo entre las distintas categorías de prisioneros. Por fuertes que fuesen las autoridades del campo, no hubiese sido posible controlar o dirigir a los miles de prisioneros sin servirse de sus antagonismos mutuos. Cuanto más antagonismo y más feroz era la lucha por el poder, más fácil resultaba controlar el campo. Divide et impera. Esta máxima que nunca debe subestimarse, tiene la misma importancia en un campo de concentración que en la alta política» (Höss, 1978:57).

Además del ejercicio del poder encaminado a que no se creasen vínculos entre los prisioneros, la atomización se reforzaba por la gran variedad y lo cambiante de las situaciones existentes. La interrelación de variables tales como la adscripción política, religiosa, racial ,criminal y nacional de los prisioneros; el trabajo; el tipo de barracón donde se alojaban ; el tiempo de estancia, las relaciones con otros reclusos, sobre todo con los prisioneros-funcionarios; y las lenguas habladas, reforzaba, aún creando nuevas normas, el dominio y la hostilidad entre los prisioneros.

Gran parte de estas distinciones estaba codificada por el sistema de triángulos, números y letras mayúsculas que cada prisionero anónimo debía llevar en el traje: un triángulo rojo denotaba un prisionero político o un resistente de los países ocupados, uno verde, un delincuente común, uno negro, a un denominado asocial o a un gitano. Dos triángulos superpuestos formando la estrella indicaba que los prisioneros eran judíos, un triángulo rosa, homosexuales y uno violeta, testigos de Jeovah. Una P señalaba que el prisionero era polaco, una $\mathrm{F}$, francés, etc. La información portada por cada prisionero tenía una funcionalidad burocrática para el control por parte de las autoridades del campo. Sin embargo, no eran indicadores que permitieran crear lazos entre los prisioneros porque, como las categorías en sí eran heterogéneas, la información que daban podía ser orientativa, pero no precisa: así, ni siquiera el dato del triángulo rojo, que llevase un prisionero "era de fiar" para otros presos políticos ${ }^{3}$. Todo el sistema de rangos, ocupaciones y distinciones, tanto en sus manifestaciones simbó-

3 Bajo la categoría prisionero político se incluía a disidentes nazis, ultranacionalistas polacos, civiles polacos atrapados en la calle, o un amplio espectro de izquierdistas de toda Europa con disputas ideológicas irreconciliables: antiguos combatientes en las brigadas internacionales durante la guerra civil española, socialdemócratas, sindicalistas, comunistas además de resistentes $u$ opositores a la ocupación nazi en sus países de origen. 
licas, como en las situaciones sociales que generaba, no solo impedía la creación de solidaridad entre unos prisioneros con grandes diferencias ideológicas, religiosas, étnicas, nacionales, de clase, y lingüísticas, sino que reforzaba la hostilidad y los antagonismos concentracionarios. Un ejemplo ilustrativo nos lo brinda la prisionera política polaca $S$ Szmaglewska, quien, en sus memorias, siempre consideró tan irreconciliables las diferencias entre las presas políticas y las comunes que en ningún momento percibe que están compartiendo la misma suerte: «Una vez rasurados todos parecen iguales, pero son como seres de diferentes planetas que nunca se entenderán entre sí. La única diferencia es el winkiel (triángulo), colocado en el pecho al lado del número: rojo para los políticos; para los ladrones, falsificadores y malversadores, verde; negro para bandidos y prostitutas. Sin embargo, para confundir, a menudo, la astuta sección política, le pone un triángulo rojo a un preso común. (...) En 1942, la casta (sic) de los comunes estaba al mando, así que ser una persona instruida significaba la muerte. Por ello, los SS les convirtieron en prisioneros funcionarios que portaban un brazalete rojo, amarillo o negro según su puesto, con las iniciales del cargo. Una de ellas era Maria Imiola, una alemana de Silesia, supervisora del bloque, solo clemente ante los sobornos de los paquetes de comida de casa. Llevaba un brazalete negro con las letras $\mathrm{L} \mathrm{A}$, un mandil negro, y una porra. Estos prisioneros causaron tanto daño como toda la SS junta» (1947:65).

Los prisioneros también habían incorporado a la jerarquía la antigüedad, si bien este reconocimiento reforzaba a su vez el sistema de rangos existente, porque la capacidad de sobrevivir estaba ligada a las condiciones del puesto de trabajo que se desempeñaba. Así narra Primo Levi, número 174.517.su primer aprendizaje de las jerarquías internas tras su llegada a finales de febrero de 1944 a Monowitz: «Sólo mucho mas tarde, y poco a poco, algunos de nosotros hemos aprendido algo de la fúnebre ciencia de los números de Auschwitz... A los veteranos en el campo se lo dice todo: la época de ingreso en él, el convoy del que formaban parte y, por consiguiente, la nacionalidad. Cualquiera tratará con respeto a los números del 30.000 al 80.000: ya no quedan más que unos centenares y marcan a los pocos supervivientes de los ghettos polacos. Hace falta tener los ojos bien abiertos cuando se entra en relaciones con un 116.000 ó 117.000: han quedado reducidos a una cuarentena, pero se trata de los griegos de Salónica, no hay que dejarse embaucar. En cuanto a los números altos tienen una nota de comicidad esencial...) (Levi 1987: 29).

De todo este complejo entramado de clasificaciones surgía la jerarquía global de los campos: desde los llamados «aristócratas", los prisioneros-funciona- 
rios, que ocupaban y se mantenían en los cargos si conseguían no caer en desgracia (kapos, jefes de barracas, administrativos, trabajadores especializados), hasta la gran masa de prisioneros de los que una gran parte, presa del hambre, de los otros prisioneros, las enfermedades, la desmoralización y las selecciones, acababan configurando la escala más baja de la clasificación, la formada por los conocidos en la jerga del campo como "musulmanes", auténticos esqueletos vivientes, sin posibilidades ni ganas de seguir viviendo, y que, en cierta forma, funcionaban como un antimodelo: en casi todas las memorias de los supervivientes los musulmanes aportaban la imagen de lo que no se quería llegar a ser.

La organización jerárquica, la atomización y la diversificación entre los prisioneros, el antagonismo entre los que ocupaban la misma suerte, llevaba a muchas víctimas a disociar las acciones que les permitiesen sobrevivir de la transcendencia que, para mantener el sistema, tenían los actos realizados. La estructura les obligaba a pensar que su conducta importaba, que podían actuar de un modo racional, que había algo que salvar: su propia vida. La paradoja que se producía era que la racionalidad de la conducta individual estaba disociada de la racionalidad de sus acciones porque éstas contribuían a mantener el sistema social de los campos de concentración tal y como había sido diseñado por los nazis. Esta trágica paradoja no es otra que la zona gris de Primo Levi: la cooperación de las víctimas en todo el proceso. Pero el sistema concentracionario no produjo solamente esta paradoja: no hay que confundir la atomización, la destrucción sistemática y brutal, el ejercicio del poder de unas víctimas sobre otras con la inexistencia de relaciones sociales surgidas precisamente del propio modelo. El diseño del antagonismo entre prisioneros mediante el establecimiento de jerarquías administrativas encabezados por una élite de prisioneros funcionarios surgía evidentemente de un reparto desigual del poder. La eficiencia del sistema estribaba en que visto desde fuera todos los prisioneros compartían la misma suerte, mientras que desde dentro ocupaban distintos rangos. La brutalidad ejercida por los kapos y otros cargos sobre el resto de los prisioneros no partía tanto del sadismo o de que muchos de ellos estuviesen allí por actos criminales como de que se habían adaptado a un sistema que había convertido el cargo mismo en la posesión más valiosa, en el mecanismo que abría más posibilidades a la supervivencia. En este sentido el objetivo de la brutalidad era guardar el cargo, o llegar a conseguir uno ascendiendo en la escala social. Pero, como a pesar de que los prisioneros funcionasen como unidades "semiautónomas", la permanencia en el cargo o el ascenso no estaba bajo su control, sino que dependía de las autoridades, de las situaciones cambiantes, y del 
azar, el propio modelo de antagonismo entre los prisioneros llevó a la larga a extender la jerarquía a la creación de relaciones sociales entre ellos que les facilitasen la subsistencia: las fisiones también conducen a las fusiones. Es decir, el ejercicio de la brutalidad y el antagonismo del diseño inicial llevó paradójicamente a la creación de varias redes de intercambio, que englobaban tanto relaciones predatorias como alianzas de dependencia mutua. La escala de las alianzas variaba: en las capas altas del sistema las redes incluían tanto a otros prisioneros como a trabajadores civiles y miembros de las SS; mientras que para los prisioneros corrientes las alianzas se basaban en la creación de "pequeñas familias" cuyos vínculos podían reforzarse por afinidades políticas, religiosas, el idioma, la nacionalidad, compartir trabajo, o barracón y siempre, como constante, el deseo de sobrevivir. Por otra parte, dadas las condiciones de vida, la estabilidad de la mayoría de estas relaciones variaba según la capacidad de mantenerse en la misma situación: más facil para los prisioneros de alto rango (funcionarios, y los que ejercían una profesión) más difícil para los corrientes.

El contexto que genera estas relaciones predatorias y de alianza sigue siendo el de la desconfianza y la pugna entre los prisioneros y el del dominio total sobre sus vidas por parte de los nazis. Por tanto la existencia de los intercambios no debe verse como una forma de resistencia o como algo que mitigase las condiciones de vida de la masa de prisioneros. Es paradójico desde la producción de entidades sin vínculos que habían diseñado, no lo es desde el punto de vista del antagonismo y del mantenimiento de situaciones de poder absolutamente desiguales.

\section{Almacenamiento, apropiación, circulación e intercambio de bienes}

Hay relativamente pocos estudios que den cuenta de la magnitud de bienes que circulaban en los campos de concentración ${ }^{4}$. Auschwitz era un almacén gigantesco donde se recogían, clasificaban y distribuían todas las pertenencias de

4 Excluimos de este apartado la explotación del trabajo de los prisioneros. Independientemente de la contradición que supuso para las altas esferas nazis el binomio trabajo-exterminio, de los planes cambiantes a lo largo de la guerra sobre la explotación de la mano de obra de los prisioneros, o de las pugnas entre las SS y el ministerio de armamento de Speer, todos los internos eran una fuente de recursos directos para las distintas ramas de las SS que controlaban la mano de obra de las mercancías humanas. La IG Farben y otras compañías ingresaban dinero en las arcas de las SS por cada trabajador esclavo. 
las víctimas llegadas desde todos los confines de Europa: mientras que en el exterior existían las restricciones propias de una economía de guerra, en Auschwitz se acumulaban los bienes con los que los miles y miles de víctimas contribuían al esfuerzo bélico alemán. Las ropas y objetos de uso eran enviadas a los ciudadanos del Reich, las divisas y el oro se destinaban al banco estatal de Berlín y servían, gracias a los servicios de la banca suiza, para manipular el cambio exterior.

\section{Almacenes centrales: Canadá}

Existían varios puntos centrales de almacenamiento de bienes necesarios para el automantenimiento del campo, tales como los de cocinas, los de las empresas agrícolas, etc. Pero el más importante era el conocido en el argot del campo como "Canadá" compuesto por varias barracas donde se clasificaban, empaquetaban y distribuían todos los bienes confiscados a los prisioneros y a todas las víctimas de las cámaras de gas de Birkenau.

Los encargados de realizar estas tareas eran los propios prisioneros, como siempre supervisados por los kapos y los SS quienes, sin embargo, no tenían acceso directo a estas inmensas riquezas. El denominado comando Canadá, compuesto por unos ochocientos prisioneros, tenía encomendada la tarea de clasificar las pertenencias que las víctimas de las deportaciones habían llevado consigo al que sería, en la mayoría de los casos, su último destino. A través de los pequeños y no tan pequeños robos que se les toleraba hacer a los miembros del comando Canadá, penetraba en el campo una fuentre diversa y heterogénea de bienes: conservas, confituras, licores, joyas, medicinas, ropas finas, pieles, divisas, cigarrillos y perfumes. $\mathrm{R}$ Vrba, que perteneció durante un tiempo a este comano, relata en sus memorias que: «una semana en Canada me enseñó más sobre el propósito de Auschwitz que lo que había aprendido en los tres meses transcurridos desde mi iniciación. Era una lección vomitiva no tanto por la brutalidad, el sadismo o las muertes esporádicas como por la sangre fría del comercialismo del lugar" (Vrba: 1964;165).

La riqueza de Canadá, la "prosperidad" de que hacía disfrutar al campo dependía de la llegada de nuevas víctimas, de los bienes que traían y de los países de procedencia. Otra de las paradojas de Auschwitz estribaba en que el incremento de muertos, llevados a las cámaras de gas directamente, favorecía a los prisioneros de los campos. 


\section{Otros prisioneros con acceso a bienes}

Pero además de los almacenes de Canadá, en Birkenau, también campo de exterminio, había una categoría especial de prisioneros que vivían aislados del resto del campo: los miembros del sonderkommando, los empleados de las cámaras de gas y del crematorio, cuya misión era preparar y llevar a cabo la ejecución de los judíos que venían en los trenes, de los gitanos, y de todos los prisioneros declarados "no aptos» en las selecciones que periódicamente tenían lugar dentro del campo. Los "sonder" 5 , es decir, los prisioneros encargados de gasear los convoyes que llegaban, siempre encontraban joyas u oro escondidos por la gente antes de ser gaseados. Uno de los pocos supervivientes, $\mathrm{Ph}$ Müller, cuenta así su paradójica situación: "por una parte teníamos que estar aislados del resto del campo, por otra, la observación estricta de este aislamiento estaba supervisada por otros prisioneros. Esto abría las puertas a la corrupción a gran escala. Cada día venían prisioneros del campo ofertando a sus socios de negocios en el Sonderkommando cigarrillos y alcohol a cambio de diamantes, dólares, relojes, dientes de oro y otros bienes valiosos organizados tras el gaseamiento. Allí se desarrollaba un comercio ilegal de insospechadas e increíbles proporciones en el que cualquiera que tuviera esperanzas de permanecer vivo trocaba cualquier cosa que ayudase a sustentar la vida» (Müller 1979:62).

\section{Lugares de intercambio}

Todos esos bienes nutrían y fundamentaban la formación de una esfera económica en el campo cuya distribución transcurría a través de las jerarquías de prisioneros. La mayor parte de los pequeños intercambios entre prisioneros corrientes tenían lugar en las letrinas, una de cuyas zonas estaba reservada a los aristócratas del campo, y en ella tenían lugar las transacciones más importantes que no estaban al alcance de la gran masa de los internos. Utilizaban como unidad de cuenta, medio de cambio, y medio de pago el cigarrillo. Los precios fluctuaban según la llegada de convoyes y la época, pero la mayor parte de memorialistas que sabían o participaban de los grandes tratos, como por ejemplo, el músico Simon Laks, fijan el precio de una hogaza de pan en unos doce ciga-

5 Los miembros de este comando, al igual que en los primeros tiempos los de Canadá, eran gaseados cada dos o tres meses 
rrillos, de un reloj entre ochenta y doscientos, o de un litro de alcohol, en unos cuatrocientos.

Las grandes transacciones en las que participaban los aristócratas y miembros de las SS o trabajadores civiles tenían lugar o bien en los barracones de trabajo o en los habitáculos de los preeminentes del campo. En estos casos se intercambiaban "favores" para los prisioneros por bienes de lujo como diamantes, divisas, relojes, vodka y alimentos. Uno de los testigos privilegiados (por su posición y por la duración de su reclusión en el campo) el músico Simon Laks recuerda en sus memorias como «Estas manipulaciones constantemente conducidas a una escala inimaginable, dieron poco a poco nacimiento a un mundo económico y social en el recinto del campo, con sus grupos de privilegiados y de desfavorecidos, con un comercio "interior" y un comercio "exterior" y un mercado de curso fluctuante... Todo esto se desarrolla bajo los ojos voluntariamente distraídos de los SS de toda graduación quienes se beneficiaban igualmente de la generosidad de los ...detenidos" (Laks 1991:102-3). En el mismo sentido, el propio Hoss, en modo alguno ajeno a que los «bienes del Reich" se desviasen de su camino a Berlín, recoge en sus memorias la siguiente descripción de los problemas surgidos en los almacenes de Auschwitz: «Los tesoros traídos por los judíos dieron origen a inmensas dificultades para el campo mismo. Era desmoralizador para los miembros de las SS, quienes no siempre eran lo bastante fuertes para resistirse a la tentación....la llegada de estos judíos con sus riquezas ofreció oportunidades inimaginables a los otros prisioneros...Con la ayuda de este dinero o anillos adquiridos con facilidad, cualquier cosa podía arreglarse con los SS o los trabajadores civiles....Quienes poseían bienes valiosos podían obtener mejores trabajos, comprar la buena voluntad de los kapos y los jefes de bloque, incluso arreglarse una estancia en el hospital donde conseguirían la mejor comida...El oro judío fue una catástrofe para el campo" (Hoss 1978:130-131).

La circulación de bienes en los campos de concentración era de tal magnitud que las primeras investigaciones judiciales sobre los campos no tuvieron lugar, como se piensa, con la entrada de los aliados, sino que fueron llevadas a cabo en su época de máxima actividad como campo de exterminio, por un juez especial de las SS, Konrad Morgen. Morgen testificó tanto en los juicios de Nuremberg como en el de Frankfurt, pero su testimonio es necesario interpretarlo. Como juez de las SS lo que él investigó en Buchenwal o en Auschwitz era la apropiación indebida de bienes "pertenecientes" a las SS, en este sentido un caso generalizado de corrupción, pero no la procedencia de esos bienes ni la 
suerte de los prisioneros. El origen de la investigación sobre Auschwitz fue el descubrimiento de un pesado paquete de oro que un SS del campo envió a su esposa.

En Auschwitz, Morgen supo que el oro procedía de las propiedades y de las dentaduras de las víctimas del exterminio que, repetimos, no es lo que el juzgaba, sino que su investigación se ceñía a que diversas autoridades del campo se estaban apropiando privadamente de los bienes del Reich. Nunca logró terminar la investigación, por el avance de la guerra, la destrucción de pruebas (hubo varios incendios provocados en los almacenes y la dispersión o desaparición de los trabajadores de Canadá) y la reorganización del campo tras la marcha de Höss. Ahora bien, tanto esta investigación como todos los intercambios que hemos descrito enlazan directamente con el peso que la mayoría de los supervivientes dan a las transacciones que en la jerga del campo se conocían como «organización».

\section{La organización}

\section{Definiciones}

Para Nadine Heftler, una jovencísima prisionera de la masa, organización es un "término que designa la acción de organizar que significa, en la jerga de los campos procurarse cualquier cosa mediante el robo o no importa que otro medio" (Heftler 1992:52).

Su compatriota Suzanne Birnbau coincide bastante con Nadine: "En el campo el verbo robar no se usaba, se había reemplazado por el verbo "organizar". Se organiza vuestro pan, vuestro culotte, o vuestro pedazo de jabón, es decir, se organizaba todo" (Birnbau 1989[1946]:83).

Si en las dos primeras definiciones organizar parece un sinónimo de robo, o una transacción de una sola dirección, en las que siguen sin desaparecer nunca este matiz, organizar ya forma parte de un complejísimo sistema de intercambios. Así, la judeo-polaca Kitty Hart, quien precisamente titula uno de los capítulos de sus memorias «organiza o muere», evoca su primer encuentro con la organización cuando nada más llegar al barracón de la cuarentena se le acerca una reclusa y le dice: "-¿Quieres comprar esta bufanda. - ¿Cuánto quieres? - Dos raciones de pan y una de salchicha». Le contesta que aun no les 
habían dado raciones y le pregunta cómo había conseguido la bufanda. "La organicé»: "Este fue mi primer encuentro con la palabra más importante en la lengua de Auschwitz: "organización" era la llave de la supervivencia. Significaba, robar, comprar, intercambiar, coger. Fuese lo que fuese lo que quisieras, necesitabas algo para permutar. Algunos pasaban cada minuto que estaban despiertos "organizando": robando a sus compañeros prisioneros, sobornando a otros, cambiando un mendrugo de pan por una porción de agua, unos billetes arrugados por la esquina más confortable de una litera" (Hart 1981:63).

La doctora Perl, que trabajaba en el hospital define así el contexto y la palabra: "Robar se convirtió en un arte, una virtud, algo para enorgullecerse. Le llamábamos organización (...) había muchos que organizaban la ración de pan del vecino, sin tener en cuenta si podría morir de hambre como consecuencia, o los zapatos del compańero de cama sin importarles si unos pies sangrantes les condenaban al crematorio. Robando pan, zapatos, agua, robabas una vida para ti mismo incluso a expensas de otras vidas" (Perl 1979[1948]:76-77).

La filóloga italiana Giuliana Tedeschi lo define así: «La guerra y la cárcel siempre han generado nuevo vocabulario. En el campo alemán durante estos años la palabra "organisieren", "organizar", era muy apropiada. "Organizar" significaba intercambiar tu pan por un jersey o tu margarina por una cucharilla. Alguien que coge un cacho de jabón dejado por otra prisionera en la ducha o lavabo está organizando y lo mismo el prisionero que oculta un cuchillo o un par de tijeras que se han caído de la cama de arriba y después las cambia por pan o el prisionero que coge un par de patatas de un cubo o apaña unas cucharadas del caldero... La forma en que los prisioneros "organizan" a expensas de todo el mundo no tiene fin. Y quien no organice, está muerto" (Tedeschi 1992:49-50).

El médico sefardita Marco Nahom introduce un nuevo matiz al incluir las donaciones en su definición: "Organizar es una palabra sagrada en el Lager. Significa todo. "Organizar" es al mismo tiempo recibir como regalo, hacer trueques con bienes, o tomar prestado de un amigo y robar de otro. En resumen, organizar es sinónimo de poseer — no importa cómo-... Uno puede tener una cena complementaria organizando unas patatas, un poco de margarina y una loncha de salchichón. Los muy ricos también pueden permitirse una cebolla o ajos" (Nahon 1989:91). El músico Simon Laks, uno de los aristócratas del campo, da una definición muy amplia que tiene en cuenta la existencia de distintas escalas: «Organizar, u organizarse, significa obtener no 
importa qué por no importa qué medio. Tanto lo adquirido mediante lo que tienes (los cigarrillos) como por la mendicidad, el trueque, el robo, el chantaje, la fuerza, incluso el homicidio. Se organiza un mendrugo de pan o diez hogazas de pan, un miserable trapo pulgoso o la lencería de seda nueva, un cigarrillo o mil cigarrillos, un litro de sopa o una marmita de sopa, un trozo de leña, una tabla, diez tablas, una mesa o... una barraca entera. Se organiza un puñado de sal, un cubo de carbón, un jergón, una medicina, una litera, todo aquello que uno puede desear si se poseen los medios para adquirirlo y las mañas típicas del campo" (Laks 1991:103).

A partir de estas definiciones (que no son ajenas a la situación como organizadores de quienes las formulan) podemos aproximarnos al complejísimo sistema de intercambios sociales existente en Auschwitz. Uno de los aspectos más reforzado en todas las definiciones precedentes es el hincapié hecho en que la relación expresada bajo el término «organizar" parte de lo inverso de dar: quitar, procurar, obtener, coger, tomar, robar. De tal forma, que aparentemente recuerdan en mucho las características que Sahlins (1965) otorga a la reciprocidad negativa como la forma "más impersonal del intercambio". Recordemos cómo en su formulación tipológica de la reciprocidad, Sahlins describe un amplio espectro en uno de cuyos polos sitúa la reciprocidad generalizada. Su tipo ideal sería el "puro don» de Malinowski, institucionalmente configurado por lo que Polanyi denominaba "relaciones simétricas", incrustadas en principios morales (a veces, jurídico-morales), tales como la "generosidad" o "compartir». Frente al altruísmo de la reciprocidad generalizada, Sahlins sitúa en el otro polo del espectro la reciprocidad negativa que recoge aquellas formas «asociales» de la reciprocidad que ejemplifican intercambios tales como el regateo, el trueque, los timos astutos, los sobornos, los hurtos, los saqueos o las incursiones para robar ganado o cosechas. Si bien Sahlins caracteriza estructuralmente la oposición entre la reciprocidad generalizada y la negativa mediante la proximidad o distancia de los vínculos sociales, nosotros proponemos aquí un modelo que de cuenta de las variaciones no como una mera oposición, sino como una compleja trama de formas variables y graduales cuyo rasgo distintivo sería la presencia o ausencia de obligaciones 6 interdependientes entre los actores, a partir de las cuales se articulan las nociones de moralidad.

El término organizar engloba una amplísima gama de transacciones y situaciones sociales. Recorre todo el espectro de la reciprocidad negativa, desde

6 No sólo en el sentido restringido de las tres obligaciones del don (MaUSs, 1924) 
las distintas clases de robo hasta el trueque, si consideramos tal el doble mercado (externo e interno), caracterizado por la utilización de varios patrones de valor. Pero esta reciprocidad negativa coexiste, merced a las relaciones sociales generadas en el propio campo, con la existencia de inestables grupos de ayuda mutua formados regularmente con la intención de organizar con más eficiencia, e incluso con instituciones, como el hospital, que se alimentan de donaciones. Es decir, el término organizar se utiliza lo mismo para trocar, para hurtar que, en algunos casos, para dar. Por ejemplo, en el punto de intercambio que se formaba en el exterior de los pabellones de Canadá, $\mathrm{R}$ Vrba, miembro del comando, describe como: "Alrededor del bloque estaban los hambrientos. Los de Canadá miraban sus caras buscando amigos o parientes a quienes separaban y les donaban restos de comida. Los médicos del campo, ellos mismos prisioneros, estaban allí, buscando drogas, medicinas que pudieses ayudarles en su desesperada tarea. Las obtenían porque todo hombre de Canadá sabía que cualquier día podía acabar en el hospital y necesitar desesperadamente un amigo" (Vrba 1964:164).

Tal variedad de situaciones y transacciones hace que sea necesario establecer la relación existente entre las circunstancias materiales y las relaciones sociales producidas en el sistema concentracionario.

\section{2. bases materiales de la organización}

La iniciación de un prisionero al campo de Auschwitz se produce mediante un ritual de llegada en el que el prisionero es despojado de todas sus ropas, calzado, paquetes, joyas, objetos personales, cabellos e incluso de su nombre. Luego les darán un uniforme desparejo o ropas ya usadas y unos zuecos de madera. Un prisionero no podía poseer ningún objeto personal: si alguno ha logrado ocultar una fotografía de sus seres queridos y esta es descubierta por algún kapo, jefe de barracón o guardián, el prisionero no solo perderá su recuerdo, sino que será severamente golpeado. Durante el primer reparto de sopa el prisionero observará que los otros tienen cucharas y escudillas, y ellos no: las han organizado: "Cuando llegas al campo eres incapaz de organizar. Te conmociona la palabra cada vez que la oyes, la odias y te preguntas a ti misma cómo es que otros tienen cosas que tú no tienes, cómo de no tener nada pueden almacenar cosas" (Tedeschi 1992: 49-50). Sin embargo, los artículos organizados no permanecen en las mismas manos durante mucho tiempo. Estaba 
prohibido poseer cosas y había revisiones periódicas en las que los prisioneros no informados (la mayoría) perdían los objetos que tanto trabajo les había costado conseguir. Cuando, a partir de 1942 se obligaba a todos los prisioneros a despiojarse, para prevenir las epidemias de tifus, los prisioneros corrientes que ignoraban cuándo se iba a producir la desinfección, perdían una vez más todas sus propiedades.

Toda posesión de objetos estaba prohibida pero era necesario proveerse de algunos para subsistir. Hemos visto el ejemplo de las escudillas y las cucharas. En el caso de los hombres estaba prohibido tener cuchillas de afeitar pero tenían que ir afeitados. Hay dos tipos de objetos sobre los que giraban la mayor parte de las transacciones y la organización: alimentos y ropas. En cierto sentido podemos decir que para el prisionero corriente estos dos elementos eran el universo de las elecciones posibles, pero también lo era para los aristócratas que fueron creando en estos dos ámbitos una esfera de bienes de prestigio:

\section{- Alimentos}

Todas las memorias están llenas de referencias a la comida, o más bien a su falta: desde los relatos de lo que V Frankl llamaba «masturbación gástrica» (hablar sobre recetas o comidas imaginarias) hasta la pericia, la habilidad o la suerte necesaria para organizar una ración extra de alimentos.

La comida que recibía un prisionero de Auschwitz no era suficiente y el agua no era potable. Tras la liberación, muchos de los médicos prisioneros escribieron artículos e incluso tesis doctorales sobre los efectos del hambre en los campos de concentración. El calculo de las calorías diarias que aportaba la dieta del campo se estima que era de entre 900-1100, (según las normas oficiales alemanes deberían de ser entre 1500-1800) lo cual explicaría no sólo la severa desnutrición general, sino también la amenorrea en las mujeres que ellas atribuían a que los alemanes echaban "polvos» en la sopa. Si a esta subalimentación le añadimos el agotamiento por las largas jornadas de trabajo, y los terribles inviernos de la Alta Silesia, comprenderemos por qué aún prisoneros que lograban organizar comida perdían entre el 30 y el $40 \%$ de su peso.

A la escasez de los alimentos contribuía el hecho de que en todo el proceso distributivo tanto los empleados de las cocinas como los jefes de barracones y sus auxiliares iban "organizando", de tal forma que las raciones que llegaban a los prisioneros siempre eran inferiores a las que salían de las cocinas. 


\section{- Ropa y calzado}

Paralelamente a la insuficiencia de alimentos, la ropa y el calzado que les daban a la llegada era insuficiente para las condiciones extremas del clima. Los zuecos de madera no servían para andar largas distancias, $y$ hay que tener en cuenta que la masa de recién llegados, salvo excepciones dominadas por el azar o por la necesidad de especialistas, (médicos, músicos, obreros especializados), eran destinados a los peores comandos (los llamados exteriores, que además de trabajar al aire libre estaban a varios kilómetros del campo). Por tanto, una de las primeras dificultades que tenía que resolver el prisionero era hacerse con buenos zapatos y ropas de abrigo.

Pero en torno a las ropas y al cuidado de la apariencia se creó una esfera de prestigio que se correspondía con el ascenso en la jerarquía del campo. Algunos comandos de privilegiados llevaban uniformes especiales (por ejemplo, las trabajadoras de Canadá, de Siemens, o las músicas). Los grandes aristócratas llevaban el traje rayado hecho con tejidos y cortes especiales, en contraste con los recién llegados que, a partir del 44 iban vestidos con ropas andrajosas, pero que no eran uniformes. La jerarquía del campo se mostraba visiblemente en el aspecto y en cómo iba vestido el prisionero. Como dice el Dr Klein: «había grandes diferencias en la calidad de los tejidos y en los cortes. La gran ambición de todo detenido era cambiar progresivamente los primeros harapos por ropas cada vez más decentes. Para lograr esta transformación no era necesario cometer crímenes, bastaba con un poco de astucia y, como en todas partes, contar con la ayuda de amigos devotos, viejos habitantes del campo. Un rayado andrajoso dejaba al detenido en las manos vengativas de sus camaradas y de sus vigilantes. Los andrajosos iban con más facilidad a los peores komandos que los que tenían una apariencia cuidada. Lo mismo ocurría con los zapatos: si había que andar era necesario conseguirse unos nuevos" (de Marc Klein, 436-437).

A veces el propio ascenso obligaba a hacerse con ropas especiales, como le ocurrió a Olga Lengyel cuando empezó a trabajar en el hospital: "El trueque era un resultado natural de las condiciones locales. No era difícil tomar parte. Yo pagué con mi ración de pan de ocho días la tela con que hacerme una blusa de enfermera. También tuve que pagar tres sopas para que me la cosiesen. Comida o ropa era un eterno problema" (Lengyel 1983[1947]:78-79). Cuando Suzanne Birnbau, gracias al azar, empieza a trabajar en el almacén de las patatas, uno de los mejores sitios para organizar, se da cuenta de que el aspecto externo influye para mantener el puesto: «Desde mi llegada al comando de las patatas com- 
prendo que vestir correctamente y el porte cuidado influyen mucho en los jefes ${ }^{7}$. He decidido, porque me lo puedo organizar gracias a las patatas, vestirme, cuanto antes, lo mejor posible. He adquirido un delantal, y un chal estampado". Algo similar ocurre con los productos de higiene, sobre todo el jabón (y en el caso de los hombres, las cuchillas de afeitar): «Debo decir que mi primera adquisición con mis primeras patatas organizadas, había sido un trozo de jabón, y todas las noches, porque era el único momento en que los lavabos estaban libres, me lavaba de los pies a la cabeza...” (Birnbau 1989 [1946]: 87).

\section{- Trabajo y alojamiento}

Una de las condiciones fundamentales para sobrevivir era el tipo de trabajo desarrollado. Pero, el trabajo también se podía organizar, unas veces gracias a los pequeños grupos de amistades, otras, sobornando a los prisioneros funcionarios: "El Arbeitsdienst toma las decisiones siguiendo criterios desconocidos, a menudo basándose abiertamente en el favoritismo y la corrupción, de manera que si alguien consigue hacerse con algo de comer puede estar prácticamente seguro de obtener un buen puesto en la Buna» (Levi 1987:37-38).

Del mismo modo, la organización también conseguía estar en los mejores sitios dentro de un barracón. Por una parte, los mejores trabajos disponían de barracones especiales. Por otra, los jefes de barracón eran los primeros interesados en contar entre sus 600 u 800 prisioneros con trabajadores bien situados en el mundo de la organización: "También podíamos ofrecer patatas a la blocova o a la stubowa, ganando así sus favores, evitar trabajos forzados y ser mejor consideradas (...) Y las numerosas blocowas, stubowas, secretarias y enfermeras de todos los bloques que disponían de fuego, eran buenas clientes, contentas de añadir a sus menús las patatas salteadas en la margarina que nos robaban" (Birnbau (1989[1946]).

\section{- Artículos de lujo}

Si bien los prisioneros corrientes no tenían acceso a artículos de lujo, el oro, las joyas, los relojes o las divisas eran una necesidad para los que intercambiaban productos y favores con los SS o con los trabajadores civiles. Estos artículos sólo circulaban en la esfera de los grandes organizadores.

7 Mientras trabaja en este comando, está directamente bajo las órdenes de SS alemanes 


\section{Relaciones sociales y organización}

Como ocurre en todo sistema social cuya base estructural es la existencia de jerarquías rígidas, éstas eran a la vez el mecanismo social que regulaba la circulación de poder y bienes en todo el campo. Es decir, la distribución de bienes no circulaba por igual entre todos los habitantes del campo sino que los bienes y servicios de lujo circulaban entre autoridades $S S$, trabajadores civiles y algunos prisioneros privilegiados siguiendo las líneas jerárquicas existentes; mientras que existían otras redes de circulación de alimentos, ropas y otros objetos entre los prisioneros situados en las escalas inferiores.

$\mathrm{Al}$ analizar la organización , o más estrictamente "tomar" como forma inicial de la circulación de bienes podemos distinguir claramente cuatro situaciones distintas:

\section{Tomar de otros prisioneros}

Se trata de pequeños hurtos para autoconsumo, pero muy generalizados. La forma expresa que revisten es el anonimato. El riesgo a evitar es que se sepa quien fue: aunque pueda parecer chocante después de lo que llevamos dicho, el robo estaba severamente castigado. Sin embargo, como a menudo se trataba de robos de comida que se consumían inmediatamente, las posibilidades de que alguien se enterase eran escasas.

\section{Tomar de otros prisioneros de diferente rango}

Se trata de robos de unos prisioneros a otros en los que la distancia social esta establecida por la jerarquía: por ejemplo el robo de alimentos en todo el proceso de distribución desde las cocinas hasta el barracón. A diferencia del caso anterior los que toman son conocidos por todos, pero se escudan en la autoridad y en el reparto desigual del poder.

Frente al anonimato de la situación anterior, este tipo de organización puede dar lugar a la formación de pequeñas alianzas entre los que lo practican y una serie de asociados, bien sea entre los notables de cada barracón, bien entre los notables del barracón y los prisioneros que se encuentran en buenos coman- 
dos de trabajo, bien entre notables de distintos barracones y kapos de trabajo. Muchos de los kapos de los mejores komandos no tenían acceso directo a los bienes porque su misión era controlar a los prisioneros, pero no andar con las mercancias, por tanto, siempre se aliaban con algunos de los trabajadores.

Riesgos: Cuando se habla de prisioneros-funcionarios da la impresión de que ocupaban el cargo para toda la vida. Pero la prohibición expresa de poseer también les afectaba a ellos. Los relatos de pequeños notables caídos en desgracia son muy numerosos en las memorias: «Una tarde, volviendo al bloque 13, constatamos estupefactas y sorprendidas, que a la blocowa Marguit y a muchas stubowas les habían rasurado los cabellos al doble cero durante nuestra ausencia. El motivo: durante una investigación de los alemanes, han encontrado, escondido en la habitación de la blockowa, oro, y gran cantidad de carne fresca, huevos, etc. Como castigo, todas ellas fueron enviadas a un comando exterior, el barracón fue cerrado y las internas distribuidas por otros» (Birnbau 1989[1946]).

\section{Tomar de los almacenes centrales}

Robos en los almacenes centrales (sobre todo en Canadá, pero también en otros almacenes), o de productos obtenidos en los comandos de trabajo. Estas situaciones generaban alianzas tanto entre los organizadores directos como entre los distribuidores pertenecientes a los rangos más altos de los prisioneros. Si bien no se trata de situaciones tan depredadoras como las anteriores, en ningún caso se pueden considerar estas transacciones una forma de redistribuir la riqueza que buscase el bien común de los internos: los intercambios afectaban a una minoría que ocupaban posiciones que les permitían organizar allí donde la gran masa de prisioneros carecía de oportunidades.

Muchos de los supervivientes, que tenían acceso directo a organizar los bienes situados en estos lugares dan cuenta de la creación de pequeños grupos de ayuda mutua, cuyo carácter era inestable debido a la situación de constante cambio que se vivía en Auschwitz. Así K. Hart, durante la época en que fue miembro de Canadá cuenta cómo: "Se formaban "pequeñas familias" en un barracón. Tres o cuatro amigas se agrupaban y organizaban las cosas juntas. Una adquiría pan, otra encontraba un pañuelo, o un lápiz o papeles, otra agua. Los miembros de un grupo se ayudaban unos a otros y desafiaban al resto. Fuera de la familia tenía que haber sobornos, dentro, amor 
y ayuda mutua" (Hart 1981:69-70). También en el hospital el Dr Nahom encontró una "pequeña familia»: «En el bloque 12 el Dr Goltz de París, el Dr Horeau de Cany (Normandía) y yo hemos formado una asociación. Hacemos fondo común con lo que cualquiera de nosotros puede organizar durante el día. Por la noche lo reunimos y tomamos nuestra comida juntos. En la parte de atrás del bloque 12 hay una pequeña barraca de madera, la morgue de Birkenau... Pero para nuestra asociación de tres médicos es un refugio providencial. Allí nos relajamos, tomamos nuestra cena cuando hemos organizado algo especial. Apartamos los cadáveres, para tener sitio y ponemos la olla de patatas, casi tocando a los muertos porque la mesa no es muy ancha" ( Nahom 1989:92-93).

Pero además de estos pequeños grupos, el mantenimiento de estas posiciones se basaba en establecer el máximo número posible de contactos con otros prisioneros de rangos más elevados. En estos casos, a diferencia de los anteriores, además del fin instrumental de organizar, los socios han de mantener las relaciones sociales directas que les permitan ser una parte estable y necesaria de las redes de intercambio. Rudi Vrba resumía así los vínculos que se generaban a partir de Canadá: "Me di cuenta de que había una jerarquía que vivía como la aristocracia, que había una escala social que uno podía subir, que los feudos se cocían, ardían y explotaban, que los ligues amorosos florecían, se consumaban y morían, que la vida en Canadá era similar a la de otros lugares: no era tan importante lo que eras como a quién conocías» (Vrba 1964: 166).

Las alianzas con los trabajadores de Canadá eran muy buscadas. Incluso los kapos de Canadá, que por razones evidentes pertenecían a la aristocracia de la organización, tenían que buscarse aliados entré sus trabajadores que eran los únicos que les podían proporcionar bienes, ya que ni los kapos ni los SS "tenían acceso al material que nosotras escogíamos. Así que sisábamos un poco aquí, un poco allí y la (a su kapo) sobornábamos, ella a su vez sobornaba a un SS menor a quien tampoco le estaba permitido llevarse el botín. Teníamos que tener cuidado en estas transacciones» (Hart 1981: 119).

Si la escala de relaciones sociales con otros prisioneros es muy amplia y compleja, también lo es la de la organización, así como las redes de intercambio. Son estos organizadores los que nutren el trueque (llamado por muchos memorialistas "mercado interno") que tenía lugar en las letrinas, donde los organizadores notables tenían lugares reservados para intercambiar con sus iguales o con los delegados de los grandes organizadores. 
El riesgo que corrían los trabajadores de los comandos era enorme. Si un prisionero era atrapado con oro, el resultado, a menudo, era mortal. Por otra parte, los miembros de Canadá sobre todo hasta 1944, eran liquidados y reemplazados por otros prisioneros cada cierto tiempo. Los que contaban con buenas redes de socios que les proporcionasen información, se organizaban traslados a otros comandos, cuando comenzaban los rumores de que el comando iba a ser exterminado.

\section{Grandes organizadores}

Traficantes de posiciones y bienes de lujo, contaban con una gran cantidad de asociados entre los prisioneros aristócratas, y con muchos dependientes con los que mantenían relaciones de "protección". Sin embargo, dada la situación de Auschwitz, no nos estamos refiriendo a redes clientelares o de asociados de carácter fijo, con obligaciones y normas definidas y socialmente sancionadas, sino a la existencia de redes de intercambio discontinúas e inestables, cuya base era la existencia de cargos en la jerarquías. Sus intercambios (que algunos prisioneros consideraban "comercio exterior") estaban reservados a otros aristócratas de igual rango, a los trabajadores civiles, autoridades y SS. Mantenían tanto una red de alianzas y sobornos con otros poderosos como una compleja red clientelar con sus subordinados que les proveían de más contactos y bienes, pero su poder emanaba de la posición ocupada en la jerarquía y de la pericia para no perderla. Mientras guardasen la posición podían beneficiarse de las transacciones con otros que también pretendían guardar la suya. De esta forma, las redes difusas de los notables se mantenían aunque cambiasen las personas. Precisamente gran parte de lo que organizaban lo transferían a los SS para comprar su permanencia en el rango. Así, en muchas ocasiones organizaban al servicio de los alemanes para mantener o mejorar las instalaciones del campo. Uno de los mejores ejemplos de grandes organizadores nos lo brinda S. Laks, director de la orquesta, cuando describe las grandes operaciones económicas de su jefe de barraca, Reinhold, a quien considera el mejor «organizador del campo", y cuya clientela más numerosa son los propios SS, "desde el comandante a los de más baja graduación" (Laks 1991:103). En un capítulo de su memoria donde narra, casi monográficamente, la carrera en Auschwitz de este singular notable, Laks cuenta como "nuestra sala de música, tan confortable, ha sido "organizada" de punta a cabo con el acuerdo de Kurt Reinhold, el 
oberkapo del komando de los carpinteros, nuestros co-residentes. Las autoridades del campo nos han dado la autorización para efectuar mejoras, pero no han manifestado el más mínimo interés por los medios empleados para realizarlas. Nos han dicho, como de costumbre "organizaros vosotros mismos" ¿cómo? ¿con la ayuda de quién? Eso no le importa a nadie. Después de unas largas negociaciones, llegamos a un pacto con K. Reinhold: el komando de los carpinteros nos suministrará el material y la mano de obra a cambio de unas lecciones de acordeón, deseadas desde hace mucho, para el contramaestre y subordinado de Reinhold, Jozef Papuga, con la condición de que él pueda tocar en nuestra sala. En la jerga del campo, esta transacción se resume en una breve formula: la orquesta "se ha organizado" una sala de música y Jozef Papuga las clases de acordeón. Las dos partes han hecho un buen negocio" (Laks 1991:103-104).

Como la orquesta de Auschwitz era un empeño del propio comandante del campo (Moreno Feliu 1995), en esta transacción Reinhold ha mantenido tanto sus relaciones con las autoridades, como con el director de la orquesta, los músicos y su subordinado Papuga.

Las relaciones entre los grandes aristócratas del campo y los miembros de las SS son fundamentales para comprender el alcance y los distintos niveles de circulación de bienes en Auschwitz. Así por ejemplo, las recepciones que da el comandante del campo Höss a Himmler y a otros altos dignatarios de las SS, no son ajenas a la circulación de bienes en el campo, como testificó en el juicio polaco sobre Auschwitz, Stanislav Dubiel, uno de los números más bajos del campo (6059), quien estuvo internado desde el 6 de noviembre de 1940 hasta el 18 de enero de 1945. Dubiel, jardinero de la familia, aporta unos datos muy interesantes sobre el aprovisionamiento de la casa del comandante, y sobre el funcionamiento de la organización entre la propia familia del comandante, los prisioneros notables y los SS. Es significativo señalar que, al igual que en el caso anterior, las autoridades alemanas descansan en la existencia de la organización y en la habilidad de los notables para conseguir bienes, tanto para su disfrute individual como para uso del campo: «La comida para las recepciones tenía que ser "organizada" por mí por orden de la Sra Höss. Antes de cada recepción la Sra. Hoss me decía lo que necesitaba, o me mandaba que hablase con Sophie la cocinera. La Sra Hoss nunca me daba dinero o cupones que sería la forma habitual de adquirir provisiones. Yo me apañaba de la siguiente manera. A través de mi amigo Adolf Maciejwski que era capo del almacén de alimentos de los prisioneros, me ponía en contacto con el director, el SS Unters- 
charführer Schebecek a quien visitaba cada semana para coger las raciones de las prisioneras que trabajaban en la casa de Höss. Un día hablando con él le conté que había escuchado una conversación de Hoss hablando de su promoción. Schebecek deseaba ardientemente un ascenso así que me preguntó si necesitaba algo para la casa de Höss. Así iniciamos nuestra relación. Cada vez que iba a buscar las raciones de las prisioneras me llevaba provisiones para la casa de Hoss. Transportaba fácilmente las cosas porque Schebecek siempre me ayudaba. Así en un año llevé tres bolsas de azúcar, cada una de $85 \mathrm{~kg}$. La señora Hoss insistía en que los SS no debían conocer estas transacciones. Le aseguré que había arreglado todo el asunto con mi amigo» (Hoss, 1978: Apéndice).

El grado de riesgos que corrían los grandes organizadores estaba limitado por su pertenencia y control de una amplia red de relaciones. Para los organizadores situados en las altas esferas, a diferencia de lo que ocurría entre las grandes masas de prisioneros, la inmediatez de la transacción estaba subordinada al mantenimiento de las redes sociales necesarias para no perder su posición. En todos estos casos las redes de relaciones estaban incrustadas en la estructura jerárquica de los campos, conectando a los aristócratas, tanto con las autoridades y SS como con las redes con que contaban entre los prisioneros.

Pero, pese a la efectividad del sistema, los grandes aristócratas no estaban exentos de riesgos: siempre podían aparecer preeminentes competidores que formaban parte de otras redes o SS que no estuviesen metidos en la organización o que buscasen su caída. Como para ellos también estaba vigente la prohibición de poseer, los grandes organizadores mitigaban los peligros dando las mercancias a un "protegido" para que se las escondiese. Aunque todo sería confiscado si les cogiesen, realmente, el apresado era el "protegido".

\section{Relaciones sociales y obligaciones}

Desde un punto de vista holista esta variedad de transacciones y de formas de llevarlas a cabo procede de las extremas y cambiantes situaciones de la vida en los campos. Como principio, la organización se basa en una defensa del auto-interés, pero la variedad de situaciones ha hecho que bajo este término se engloben tanto transacciones unidireccionales que no necesitan socios, vínculos o relaciones sociales, como la repetición de estas transacciones que supone que ciertos intercambios de bienes tiendan a realizarse con socios conocidos o 
con prisioneros que ocupan posiciones conocidas. Sin embargo, dado que en Auschwitz, caracterizado por la desaparición y muerte de los prisioneros de cualquier rango, no podían existir ni relaciones a largo plazo ni posibilidades de reproducción de estas mismas relaciones sociales, es más apropiado que consideremos el amplísimo espectro de niveles de intercambio como parte de un sistema de relaciones posicionales y no como un sistema de relaciones interpersonales. Salvo excepciones, todas las relaciones con socios eran de corta duración, discontinúas e inestables, aún en el caso de los mejor situados en la jerarquía del campo.Por ello, aún en los intercambios más jerárquicos, como los flujos siempre podían reconvertirse en unidireccionales, los contraflujos eran contingentes. Por los mismos motivos, la presencia o ausencia de obligaciones también era contingente.

Bajo el término organizar coexisten varias formas de distribución del poder de unos prisioneros sobre otros, varios tipos y niveles de transferencias, y varias esferas de intercambio. A veces, organizar señala un mero objetivo instrumental del acceso a ciertos bienes necesarios para subsistir; otras, nos indica una utilización de ciertas redes sociales difusas e inestables. En el primer caso, la reciprocidad negativa se muestra como una situación inversa a la del puro don (ya no se sabe quién DA/TOMA qué de quién, o en qué consiste o cómo existe la obligación de recibir y devolver), es decir sería el puro QUITAR. En el segundo, como las relaciones son posicionales, tampoco podemos referirnos a una articulación social de vínculos interpersonales. Por eso, desde un punto de vista global, la característica de organizar es la ausencia de un sistema estructurado de obligaciones y por tanto debemos relacionarla con una suspensión de los principios sociales de la moralidad.

\section{Organización y moralidad}

Se ha insistido mucho en los últimos tiempos en considerar o analizar a los verdugos no desde el punto de vista de la aberración psicológica, sino desde la perspectiva de que eran "ciudadanos ordinarios" (Katz 1993, Browning 1992, Goldhagen 1996). Pero las víctimas (ninguna de las cuales eligió ser víctima) eran ciudadanos ordinarios, en su mayor parte alejadas de los sistemas penales, cumplidoras de las leyes y de las normas culturales de sus comunidades, que nunca supusieron ni que "tomarían" cosas ni que les "tomarían" sus cosas. Sin embargo, tras la expropiación total que sufrían a su llegada al campo, el siste- 
ma exigía que organizasen: pero tomar, frente a dar, en el mundo corriente de antes y después de Auschwitz en que vivían la mayoría de los prisioneros, pertenece al terreno de lo moralmente ambiguo, cuando no ilícito. En este sentido es relevante destacar que el término organizar se aprendía en el campo, para dar cuenta, específicamente, de las transacciones que allí tenían lugar. Esta ambigüedad moral sólo desaparece en aquellos prisioneros que, a pesar de la inexistencia empírica de mecanismos, redes sociales o instituciones redistributivas, nos presentan, en sus memorias, la organización como una forma igualitaria de redistribución, cuya base era tomar de los alemanes para que entrasen en el campo bienes que mejorasen la situación de los internos. Para el resto subyace el dilema sobre la relación existente entre los mecanismos que les permitieron sobrevivir y la adaptación a la inversión moral de Auschwitz.

Las memorias corroboran la existencia generalizada de robos entre prisioneros, y hay numerosísimos relatos de cómo o cuándo a uno le han robado; sin embargo, la dimensión moral del tomar frente al dar hace que haya muy pocos ejemplos (y sólo en momentos muy dramáticos) en que se cuente un robo realizado por el propio memorialista. Y cuando se hace, a menudo se muestra imbricado dentro de una cadena abierta de robos y contra-robos: "Una vez pretendía coger a tientas mis zapatos en plena noche porque necesitaba salir... y me encuentro un botín pero me resulta imposible encontrar el otro, un zapato bajo tipo "sport". Adquiero rápidamente la convicción de que me lo han "organizado"... Si mañana por la mańana yo no tengo el otro zapato a la hora de la llamada y para salir a trabajar, el cielo me caerá sobre los hombros». Furtivamente se pasea entre las filas de literas hasta que "me paro ante una en la que parece que todo el mundo ronca y donde el muestrario de zapatos es especialmente atractivo; escojo rápidamente un botín del pie derecho, poco más o menos de mi talla, que no tiene mala pinta. Todo el mundo ronca, nadie se mueve y yo creo que nadie me ha visto. iperfectop" (N. Heftler 1992: 91-92). El anonimato es total: nunca menciona nadie la organización de los dos zapatos.

Otros supervivientes establecen un código de a quién es lícito "organizar". Kitty Hart en su primera noche en el campo había escondido un mendrugo de pan en su blusa. A la mañana siguiente no estaba: "o se me cayó durante la noche o me lo habían robado. volví a la litera a buscarlo, no estaba allín. Su vecina de litera, una gitana con quien había hablado antes de dormir se había muerto durante la noche: "Pero estaba la gitana muerta, la palpé y vi que tenía varias raciones de pan escondidas. Dudé un momento, después me apropié del pan y de su camisa que era menos basta que mi chaqueta del ejército y podía 
llevarse sin que se notara. Fue la primera vez que tomé algo de los muertos. No sería la última» (Hart 1981: 66-67). Su madre, que trabajaba en el hospital, y ella establecen como regla moral nunca tomar nada de los vivos: "La vida en Auschwitz era una cuestión de organizar, de solucionar las necesidades desnudas cuando las encontrases. Si tomábamos algo, debería ser de los muertos. ¿Para qué le servían sus ropas o sus raciones a los muertos? Mi madre en el hospital tenía muchas oportunidades para coger pan o una ocasional loncha de queso o de salchichón de un cadáver... Robar a los vivos o a los semivivos era acelerarles el camino hacia la muerte. Organizar las reliquias de los muertos era adquirir material que ayudaba a mantener vivos a los vivos, a respirar a los semivivos con la suficiente fuerza para que sobreviviesen hasta que se abrieran las puertas a un mundo exterior mas libre y mas apacible» (Hart 1981:71).

No conocemos ningún caso de memorias que describan el problema de la ambigüedad moral cuando se tomaba algo de los almacenes de los alemanes. Sin embargo, muchos prisioneros políticos presentan la organización como un mecanismo redistributivo con fuertes connotaciones de resistencia política. Así la prisionera política polaca Lewinska describe la organización en términos de resistencia heroica: «Es gracias a vosotras, bravas organizadoras, que los alemanes no nos han podido exterminar a todos" (Lewinska 1945:77). «La base material de la vida en el campo estaba constituída por lo que nosotros llamábamos "organización", término que en el argot de Oswiecim significaba un robo cometido en los almacenes del campo. Esta organización-robo era nuestra respuesta y nuestra defensa contra la privación de todos los bienes materiales..." (:145-146). En su descripción, no sólo desaparecen los robos y todas las relaciones predatorias entre los prisioneros, sino que las complejas redes de circulación de bienes quedan reducidas a una forma de intercambios redistributivos dotados no sólo de rectitud moral, sino del poder subversivo de los combates clandestinos, a pesar de que en el medio de las transacciones saliesen beneficiados los SS y los aristócratas del campo, tanto en cuanto al acceso a bienes e información como al mantenimiento de los rangos y los antagonismos entre prisioneros y de que tales bienes nunca llegasen a la masa de prisioneros: "La organización era el dominio donde nos reencontrabamos todos... Los soldados alemanes estaban al corriente pero ellos no tenían acceso a los almacenes. No eran raros los casos en los que los soldadotes triunfantes del Reich alemán se hacían pagar los servicios prestados a los detenidos. Estar en buenos términos con ciertos detenidos les tenía cuenta a nuestros amos. Por este medio la organización atravesaba las alambradas del campo. Era sobre todo el oro y los relo- 
jes los que iban a parar a manos de los particulares alemanes. Los vigilantes y jefes obtenían grandes beneficios de su situación en el campo. El ministro de finanzas del Reich ignoraba cómo se enriquecían" (Lewinska 1945:147). "Por esta misma vía penetraban productos de fuera: aguardiente, cigarrillos, y objetos de lujo para los aristócratas del campo. Pero el oro que salía del campo no estaba siempre destinado a satisfacer los caprichos de esta "aristocracia". Servía también para procurarse medicinas o para redimir seres humanos" (:147).

En un sentido similar, otros prisioneros resuelven el dilema moral que suponen los robos a otros prisioneros en términos de los antagonismos segmentarios establecidos en la jerarquía del campo, distinguiendo a los presos políticos que ejercían la rectitud moral de la redistribución a partir de los bienes de lo almacenado por los alemanes, de los presos comunes que robaban de forma generalizada a los otros prisioneros. Así para la prisionera política polaca S. Szmaglewska organizar parece tener un doble significado, uno propio de los presos comunes, otro de los políticos: [los presos comunes] "han distorsionado el significado de la palabra "organizar" en Oswiecim [nombre polaco de Auschwitz]. En el lenguaje de un prisionero político la palabra "organizar" significa adquirir una cosa que necesitas sin perjudicar a otro prisionero como por ejemplo, tomar una camisa de un almacén. Pero tomar la camisa que alguien había lavado y puesto a secar en la hierba no es organizar, es robar». Nos brinda más ejemplos, así "cuando un prisionero le da a otros prisioneros unas piezas de pan conseguidas en el almacén, esto es organizar. Pero si el supervisor del bloque toma las piezas de las raciones de otros prisioneros y se las pasa a los privilegiados, esto es robar: La mentalidad criminal es incapaz o no quiere distinguir entre robo y organización» (Szmaglewska 1947:66-67).

Tomado como elemento de lucha, expresado en los términos familiares de la épica, eliminado el tomar de otros prisioneros, no hay ambigüedad moral en la organización. En este sentido, "organizar» era robar, pero lo apropiado y acumulado por los alemanes, y por tanto el "tomar" se interpreta como una forma de resistencia. Así, Olga Lengyel nos dice «Pero el término "organización" contenía un matiz que no capté durante algún tiempo. Significaba no sólo robar, sino robar a expensas de los alemanes. De esta forma, robar se ennoblecía, resultaba incluso benéfico para los internados. Cuando los empleados de Canadá o de los almacenes de ropas robaban ropa caliente para sus mal vestidos camaradas, esto no era un robo común, era un acto de solidaridad social. Cuanto más se tomase de los alemanes y se enviase a los barracones del campo para que lo usasen los prisioneros, en vez de enviarlo a Alemania, más 
se ayudaba a la causa. En este sentido robar y organizar no eran sinónimos" (Lengyel 1983 [1947]: 95). Olga Lengyel quiere presentar el modelo, moralmente aceptable e ideológicamente irreprochable, de lo que debería haber sido organizar, pero este modelo choca con la realidad empírica de Auschwitz: "Desgraciadamente no siempre era fácil trazar la línea. Y el término organizar a menudo se usaba para justificar robos rastreros... Bajo este pretexto algunos internos, presionados por el hambre, robaban las raciones miserables de sus vecinos. Muchos mal vestidos cogían los harapos de otros en el lavabo" (Lengyel 1983 [1947]:96). Sus observaciones y un robo sufrido hacen ver a Olga que no se trata de una mera distinción entre prisioneros políticos y comunes, entre prisioneros morales de las clases altas y el resto de los internos: "en el crisol de Auschwitz-Birkenau, las barreras sociales y los prejuicios de clase desaparecían. Pobres campesinas simples e ignorantes hacían maravillas "organizando" y dieron pruebas de generosidad, mientras que mujeres cultivadas, cuya moralidad nunca había sido puesta en duda, pretendían "organizar" en detrimento de sus camaradas" (:96).

\section{Conclusión}

La mayoría de los memorialistas de Auschwitz narran sus encuentros con la organización en términos morales o más precisamente en términos de justificaciones de conducta a partir de una ruptura y de una pugna con los valores morales conocidos. Organizar, en todas sus variedades, se nos muestra a la vez como consecuencia de la suspensión de la moralidad, y como génesis de las normas surgidas e incrustadas en el universo social concentracionario. La discontinuidad entre las relaciones sociales de antes y después de Auschwitz y las basadas en la inmediatez del tomar de otros que dominaba la traumática experiencia del campo, ofrece una ilustración tanto de la imbricación de las moralidades en los sistemas sociales que las soportan, como de la dificultad de evaluar en abstracto una situación cuyo punto de partida no es la elección, sino la suerte moral.

Tanto Mauss como Polanyi vincularon el estudio de la reciprocidad al de las ideas sobre la moralidad. La incrustación de la reciprocidad en las instituciones sociales, políticas, religiosas, económicas y de parentesco delimita un amplio espectro de relaciones que abarca tanto la complejidad del don y las obligaciones ante parientes, aliados y vecinos característicos de la reciprocidad 
generalizada, como la ausencia de obligaciones que define la reciprocidad negativa. En otras palabras, mientras que la reciprocidad generalizada se basa en una moralidad compartida, la negativa se da en situaciones de irrelevancia ${ }^{8}$, ruptura, transformación o suspensión del orden moral.

El referente moral es fundamental para que el concepto de reciprocidad resulte útil y se diferencie sustancialmente del de intercambio. Sin embargo, resulta esencial analizar las facetas positivas y negativas de la reciprocidad simultáneamente. Consideremos tres elementos básicos que operan en la organización social: 1) TOMAR para DAR, 2) PEDIR para RECIBIR y 3)GUARDAR para SER. En situaciones en las que una moralidad compartida sustenta y canaliza las relaciones sociales, la primera parte del proceso permanece invisible y aparecen sólo los aspectos positivos: DAR/ RECIBIR/ SER. Los aspectos negativos de cada par permanecen ocultos. En situaciones de quiebra o suspensión del orden moral los grupos sociales recalcarán los componentes negativos: TOMAR/PEDIR/GUARDAR . Sin embargo, ambos pares suelen formar parte de procesos relacionados y pueden darse tanto en contextos sociales con una hegemonía moral particular, como en contextos con ruptura de hegemonía moral (con moralidades diversas o conflictivas) o con suspensión de moralidad. Esta complejidad queda patente en el análisis etnográfico de Auschwitz, donde la suspensión de la moralidad ofrecía mano a mano con la organización, la única posibilidad de supervivencia material.

\section{Bibliografía}

Bauman, Z. (1989): Modernity and the Holocaust, Oxford: Polity Press.

BIRnbau, S. (1989) [1946]: Une Française Juive est Revenue, Paris, Hérault Éditions. BRownING, C. (1992): Ordinary Men: Reserve Police Battalion 101 and the Final Solution in Poland, New York, HarperCollins.

CzeCH, D. (1978): Konzentrationslager Auschwitz, en Auschwitz Nazi Extermination Camp, Varsovia, Interpress Publishers.

8 En muchas sociedades como los dones no existen en abstracto, no existe ninguna obligación de dar a los extraños. Por ello, la moralidad sería irrelevante, al tiempo que, si existiesen transacciones estaríamos tratando casos de reciprocidad negativa. Creemos que este criterio es más preciso que el aplicado por Sahlins cuando se refería a la "distancia social" como criterio diferenciador de los tres tipos de reciprocidad. 
CzeCH, D. (1990): Auschwitz Chronicle 1939-1945, New York, Henry Holt and Co.

Czech, D. (1994): “The Auschwitz Prisoner Administration», en GuTMAN, Y., y BERENBAUM, M. (Eds), Anatomy of The Auschwitz Death Camp, Bloomington, Indiana University Press.

Dwork, D., y VAN Pelt, R. (1996): Auschwitz, New York, WW. Norton and Co.

FERENCZ, B. (1979): Less than Slaves, Harvard, Harvard University Press.

GoldHAGEN, D. (1996): Hitler's Willing Executioners: Ordinary Germans and the Holocaust, New York, Alfred A. Knopf.

GOULDNER, A.W. (1960): «The Norm of Reciprocity: A Preliminary Statement», en American Sociological Review, v. 25, n. 2.

HART, K. (1981): Return to Auschwitz, London, Sidgwick\&Jackson.

HeFtLer, N. (1992): Si tu tén sors: Auschwitz 1944-1945, Paris, La Découverte.

Höss, R. (1978): "Autobiografia», en Auschwitz seen by the SS, Oswiecimiu, Publications of Panstwowe Muzeum.

KATZ, F. (1993): Ordinary People and Extraordinary Evil, State University of New York Press.

LaKs, S. (1991): Mélodies D’Auschwitz, Paris, Cerf.

Langbein, H. (1975): Hommes et Femmes à Auschwitz, Paris, Fayard.

Lengyel, O. (1983) [1947]: Five Chimneys: The Story of Auschwitz, New York, Howard Fertig.

LEVI, P. (1987): Si esto es un hombre, Barcelona, Muchnik Editores.

LEVI, P. (1989): Los hundidos y los salvados, Barcelona, Muchnik Editores.

LEWINSKA, P. (1945): Vingt Mois à Auschwitz, Paris, Éditions Nagel.

Mauss, M. (1968 [1923-24]): Essai sur le don. Forme et raison de l'échange dans les sociétés archaïques en Mauss, M. Sociologie et anthropologie, Paris: Presses Universitaires de France.

Moreno Feliu, P. (1995): «Voces de Auschwitz: la música en los campos de concentración", en Raices, 1995, n. 22.

MÚlLeR, F. (1979): Auschwitz Inferno, London, Routledege and Kegan Paul.

NAHON, M. (1989): Birkenau, the Camp of Death, Tuscaloosa, The University of Alabama Press.

NAROTZKY, S., y MORENO, P. (2000): «La reciprocidad olvidada: reciprocidad negativa, moralidad y reproducción socialn, en Hispania. Revista Española de Historia, CSIC, vol. LX/I, n. ${ }^{\circ} 204$, pp. 127-160.

Naumann, B. (1966): Auschwitz: A Reprt on the Proceedings Against Mulka and Others Before the Court at Frankfurt, New York, Frederick A Praeger Publishers. 
PAwelczYnsKa, A. (1979): Values and Violence in Auschwitz: A Sociological Analysis,

Berkeley, University of California Press.

PerL, G. (1979) [1948]: I was a Doctor in Auschwitz, New York, Arno Press.

Polany, K. (1971 [1944]): The Great Transformation, Boston: Beacon Press.

SaHLINS, M. (1965): "On the Sociology of Primitive Exchange», en Banton, M. (De)

The Relevance of Models for Social Anthropology, London, Tavistock Publications.

SAHLINS, M. (1979): «Hombre pobre, hombre rico, gran hombre, jefe: ripos políticos de Melanesia y Polinesia", en LloberA, J.R. (Ed), Antropología politica, Barcelona, Anagrama.

SERENY, G. (1995): Albert Speer: His Battle with Truth, New York, Albert A. Knopf.

SOFSKY, W.(1995): L'Organisation de la Terreur, Paris, Calmann-Lévy.

SPEER, A. (1969): Memorias, Barcelona Paza y Janés.

Strecelecka, I. (1994): “Women", en Gutman, Y., y Berenbaum, M. (Eds), Anatomy of the Auschwitz Death Camp, Bloomington, Indiana University Press.

SZMAGlewSKA, S (1947): Smoke over Birkenau, New York, Henry Holt and Company.

Tedeschi, G. (1992): There is a Place on Earth: A Woman in Birkenau, New York, Pantheon Books.

Trial of Major War Criminals Before the International Military Tribunal (1947): vol. XX, Nuremberg.

VRBA, R. (con A. BESTIC) (1964): Escape from Auschwitz: I cannot forgive, New York, Grove Press. 